\title{
ПРОТОЧНЫЙ БИОРЕАКТОР ДЛЯ ИССЛЕДОВАНИЯ БАКТЕРИАЛЬНО-ХИМИЧЕСКОГО ВЫЩЕЛАЧИВАНИЯ СУЛЬФИДНЫХ МЕДНО-НИКЕЛЕВЫХ РУД И КОНЦЕНТРАТОВ
}

\author{
А.А.БАЛЫКОВ, О.О.ЛЕВЕНЕЦ, Т.С.ХАЙНАСОВА \\ Научно-исследовательский геотехнологический центр Дальневосточного отделения Российской академии наук, \\ Петропавловск-Камчатский, Россия
}

\begin{abstract}
Бактериально-химическое выщелачивание металлов зарекомендовало себя как альтернативная технология гидрометаллургической переработки и обогащения рудного сырья благодаря снижению капитальных затрат и вредного воздействия на окружающую среду. Различные технологические схемы биовыщелачивания успешно применяются для переработки сульфидных концентратов, бедных сульфидных и окисленных руд. Одной из важнейших задач дальнейшего развития данной отрасли биотехнологии является усовершенствование биореакторных установок (в частности - проточного типа), снабжение их системами дополнительного контроля технологических параметров. В статье кратко освещены основные результаты, полученные в НИГТЦ ДВО РАН в рамках исследований биовыщелачивания сульфидной кобальт-медно-никелевой руды. Приведено описание биореактора для исследования биовыщелачивания в периодическом режиме и реакторной установки каскадного типа для исследования биовыщелачивания в непрерывном режиме. Представлена модель усовершенствованного биореактора для бактериально-химического выщелачивания сульфидной руды. Приведено подробное описание микроконтроллерного способа управления технологическими параметрами. Область применения представленных результатов - лабораторные, укрупненные и полупромышленные испытания технологии чанового и реакторного бактериально-химического выщелачивания сульфидных руд.

Ключевые слова: бактериально-химическое выщелачивание; биовыщелачивание; биогидрометаллургия; сульфидная руда; никель; биореактор; микроконтроллерное управление; 3D-моделирование; массообмен; газообмен; технологические параметры
\end{abstract}

Как цитировать эту статью: Балыков А.А. Проточный биореактор для исследования бактериальнохимического выщелачивания сульфидных медно-никелевых руд и концентратов / А.А.Балыков, О.О.Левенец, T.С.Хайнасова // Записки Горного институга. 2018. Т. 232. С. 383-387. DOI: 10.31897/PMI.2018.4.383

Введение. В сравнении с традиционными способами переработки рудного сырья бактериально-химическое выщелачивание (биовыщелачивание) характеризуется более низкими энергопотреблением и капиталовложениями наряду с уменьшением вредного воздействия на окружающую среду $[2,5,9,11]$. В основе данной технологии лежит метод интенсификации процесса извлечения ценных компонентов (меди, никеля, цинка, золота, урана и т.д.) или вредных примесей (мышьяк) из руд и минералов с использованием окислительной активности хемолитотрофных микроорганизмов [12-14].

На месторождения сульфидных медно-никелевых руд приходится около 30 \% запасов никеля. Никельсодержащие сульфидные руды обычно концентрируют и затем направляют на высокотемпературную переработку. Однако руды, в которых пентландит $\left((\mathrm{NiFe})_{9} \mathrm{~S}_{8}\right)$ находится в прочных сростках с пирротином $\left(\mathrm{Fe}_{1-x} \mathrm{~S}\right)$, с трудом поддаются традиционным методам переработки. На долю пирротина может приходиться от 10 до 50 \% сульфидной составляющей никелевых сульфидных руд, что обуславливает его значительную роль в химии выщелачивания. При окислении пирротина высвобождается как трехвалентное железо, окисляющее никельсодержащие сульфидные минералы, так и двухвалентное железо, служащее источником энергии для железоокисляющих микроорганизмов в пульпах биовыщелачивания [14].

Для разработки эффективных технологических схем биогидрометаллургической переработки руд и концентратов процессы биовыщелачивания исследуют на лабораторном и полупромышленном уровнях в периодическом и непрерывном (проточном) режимах, используя два основных типа реакторов - реактор с механическим перемешиванием и эрлифтный перколятор. В промышленных масштабах наряду с кучным и чановым биовыщелачиванием применяют биовыщелачивание в биореакторах проточного типа, представляющих собой каскад биореакторов с механическим или аэродинамическим перемешиванием $[4,6,8,14]$. 


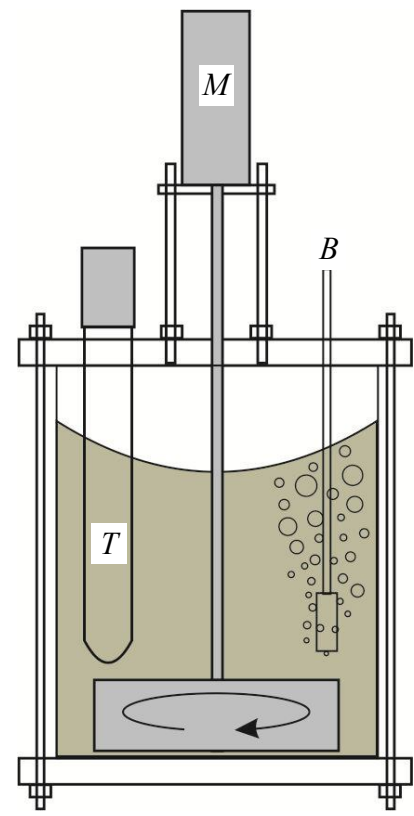

Рис.1. Схема реактора для проведения биовыщелачивания

$M$ - механическая мешалка;

$B$ - система подачи воздуха для аэрации пульпы; $T$ - терморегулятор

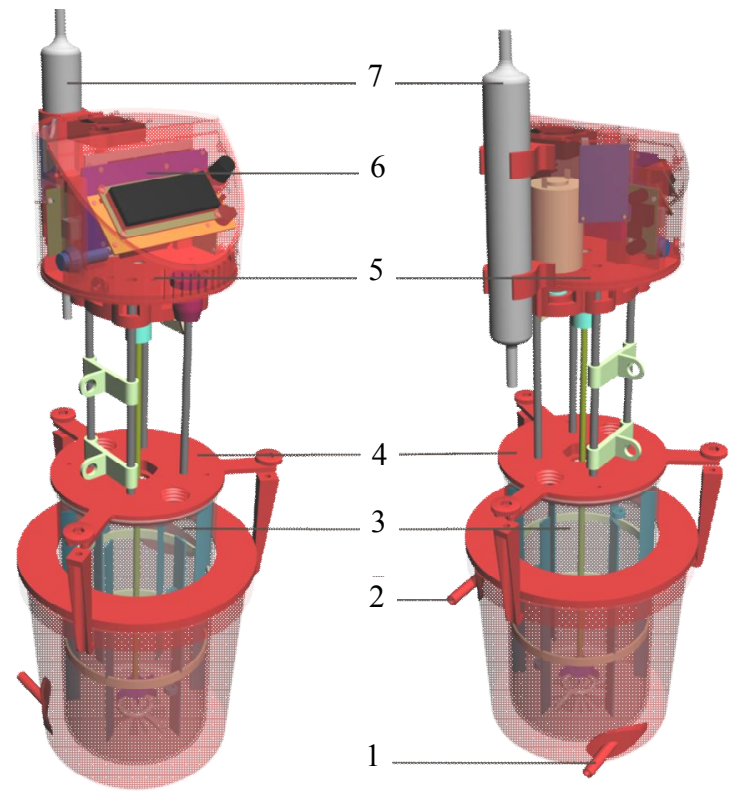

Рис.2. Общий вид реактора

1 - штуцер подачи теплоносителя в рубашку реактора из термостата; 2 - штуцер отвода теплоносителя из рубашки обратно в термостат; 3 - рабочая емкость; 4 - крышка реактора; 5 - корпус для электронных компонентов; 6 - лицевая панель с элементами индикации и управления; 7 - холодильник для конденсации испарений при аэрировании пульпы

Различные вариации технологии биовыщелачивания успешно применяются для переработки сульфидных концентратов, бедных сульфидных и окисленных руд. Одним из направлений дальнейшего развития данной отрасли биотехнологии станет усовершенствование биореакторных установок (в частности - проточного типа), снабжение их системами дополнительного контроля технологических параметров [15].

В Научно-исследовательском геотехнологическом центре Дальневосточного отделения Российской академии наук разработаны и созданы реакторы и реакторные установки для проведения исследований процесса бактериально-химического выщелачивания в периодическом и непрерывном режимах:

1) реактор для проведения биовыщелачивания в периодическом режиме, с однократной загрузкой пульпы и выгрузкой ее после окончания процесса (рис.1);

2) установка каскадного типа для биовыщелачивания в непрерывном (проточном) режиме, состоящая из контактного чана, в который загружается пульпа, и четырех реакторов, сконструированных по схеме, представленной на рис.1; в первый реактор пульпа из контактного чана подается с помощью перистальтического насоса с регулируемой скоростью протока, а из первого во второй и последующие реакторы пульпа поступает самотеком [1].

Методология. Проведен комплекс экспериментальных исследований бактериальнохимического выщелачивания сульфидной кобальт-медно-никелевой руды месторождения Шануч (Камчатка) как в периодическом [3], так и проточном [1] режимах. Достигнутые показатели извлечения металлов в раствор (80\% Ni и $\mathrm{Co}, 52 \% \mathrm{Cu})$ превосходят показатели извлечения металлов из схожих типов руд, полученные рядом зарубежных исследователей $[7,10]$.

В целях оптимизации исследований процессов бактериально-химического выщелачивания разработан более совершенный биореактор. Наиболее важными особенностями нового реактора являются реализация микроконтроллерного способа управления технологическими параметрами и их регистрации, а также улучшенные в сравнении с предыдущей версией характеристики массо- и газообмена.

Общий вид реактора представлен на рис.2. Реактор состоит из емкости объемом 2 л (рабочий объем 1,8 л), системы агитации (перемешивания) пульпы, системы аэрации пульпы, системы термостатирования и системы управления с подсистемой сбора, индикации и регистрации информации. 
Электронный блок управления (рис.3) создан на основе микроконтроллера АТmega2560-16AU и выполняет задачи по измерению и поддержанию на заданном уровне температуры пульпы, оборотов вала системы агитации пульпы, обеспечению интерфейса с оператором, регистрации технологических параметров и отчетов о нарушениях работы системы на карту памяти через заданные интервалы времени, обмену информацией с персональным, планшетным компьютером или смартфоном, а также обеспечивает возможность получения информации и контроля над системой через SMS-сообщения с мобильного телефона.

В отличие от предыдущей версии конструкции, терморегулирование содержимого рабочего объема реактора осуществляется не погруженным в пульпу нагревателем, а с помощью внешнего термостата. Термостат представляет собой отдельную емкость объемом 3 л, в которой установлен насос для прокачки теплоносителя в рубашку реактора и электронагревательный элемент (ТЭН) мощностью 900 Вт. Для управления мощностью нагревателя разработано и установлено устройство фазового регулирования переменного напряжения на микроконтроллере ATtiny13A-PU, который открывает силовой симистор BTA41-600. При этом уровень подаваемого на ТЭН напряжения изменяется в пределах от 1 до $95 \%$ от сетевого. Температура содержимого реактора регулируется на основании показаний цифрового датчика температуры DS18B20. Расчет необходимого уровня мощности осуществляется микроконтроллером реактора по пропорционально-интегрально-дифференциальному алгоритму (ПИДалгоритму) и передается по цифровой линии микроконтроллеру термостата. Благодаря использованию мощного нагревательного элемента и плавному изменению его мощности по ПИДалгоритму, достигается быстрое и точное регулирование температуры пульпы. Шаг регулирования и температурный гистерезис составляют $0,1^{\circ} \mathrm{C}$. Диапазоны регулирования ограничены применением материалов конструкции и в управляющей программе микроконтроллера установлены в пределах от температуры окружающей среды до $70{ }^{\circ} \mathrm{C}$.

Улучшение характеристик массо- и газообмена достигнуто за счет использования на внутренней стенке рабочей емкости реактора отбойников (baffles баффлы) для пульпы и агитатора турбинного типа оптимальных размеров (рис.4, 5). Это стало возможным благодаря применению современных способов прототипирования: 3D-моделирования и 3D-печати методом послойного наплавления. Крышка, корпус для электроники, лицевая панель, корпус и шкивы редуктора вала агитатора, кронштейны для теплообменника (холодильника) и для ротаметра системы аэрации и многие другие детали конструкции также изготовлены методами $3 \mathrm{D}$-моделирования и $3 \mathrm{D}$-печати.
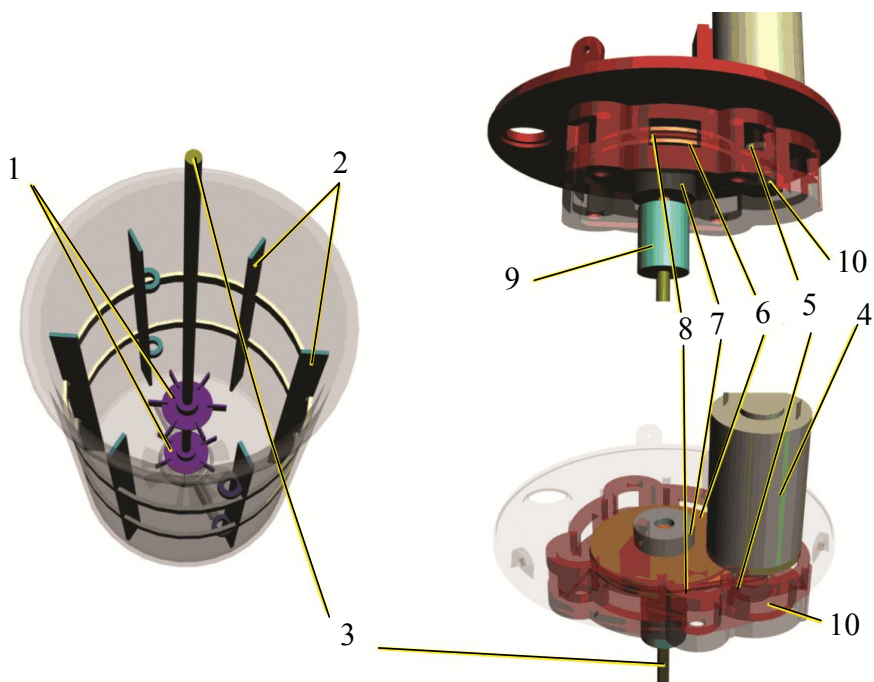

Рис.4. Элементы системы агитации пульпы

1 - агитаторы турбинного типа; 2 - отбойники; 3 - вал; 4 - коллекторный электродвигатель; 5 - малый шкив редуктора; 6 - большой шкив редуктора; 7 - подшипники большого шкива редуктора; 8 - ремень редуктора; 9 - соединительная муфта; 10 - подшипник малого шкива редуктора 


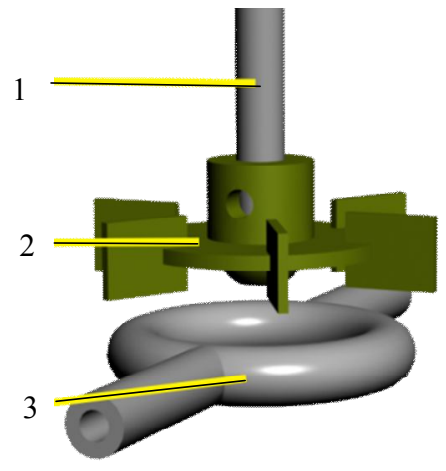

Рис.5. Элементы системы агитации и аэрации пульпы

1 - вал; 2 - агитатор турбинного типа; 3 - распылитель воздуха

Микроконтроллерное управление с обратной связью и наличие понижающего редуктора с передаточным числом 1:5 позволяют точно поддерживать обороты вала системы агитации пульпы на заданном уровне в широких пределах - от 150 до 1000 об/мин. Напряжение, подаваемое на обмотки электродвигателя, рассчитывается исходя из текущих оборотов на основании данных, поступающих с датчика вращения, по пропорционально-интегральному алгоритму. В качестве датчика вращения используется щелевой фотопрерыватель, отправляющий 1 импульс за полный оборот вала.

Система аэрации пульпы (рис.5) состоит из подводящих воздух трубок, ротаметра-регулятора и расположенного под агитатором распылителя. Распыли-

тель представляет собой полое кольцо с двумя диаметрально расположенными подводными патрубками и 16 отверстиями малого диаметра на нижней поверхности. Достаточно мелкие пузырьки воздуха, поднимаясь к поверхности, попадают на лопасти агитатора и, разбиваясь на еще более мелкие, вовлекаются в интенсивный высокотурбулентный поток пульпы, что способствует интенсивному растворению в ней газов.

Поскольку при прохождении газа через пульпу с температурой выше окружающей среды он насыщается испарениями (водяной пар, пары серной кислоты), которые затем выносятся из реактора, система аэрации была дополнена холодильником с контуром принудительного охлаждения для конденсации испарений и возврата их обратно в реактор. Для этих целей емкость реактора была герметизирована. Вода в контуре охлаждения перекачивается циркуляционным насосом между двумя теплообменниками. В первом теплообменнике охлаждаются реакторные газы, во втором вода передает тепло на элементы Пельтье, с которых далее - на воздушные радиаторы с вентиляторами.

Управление реактором осуществляется с помощью меню, реализованного на символьном ЖК-дисплее на две строки по 16 символов и инкрементальном энкодере с кнопкой. Для удобства настройки нажатие кнопки и изменение параметров энкодером сопровождаются звуковыми сигналами. Настройки сохраняются в энергонезависимую память микроконтроллера и остаются неизменными при отключении питания.

Встроенные модули SD-карты памяти и часов с календарем позволяют фиксировать параметры работы реактора, такие как температура пульпы, скорость вращения вала агитатора пульпы, температура окружающего воздуха, подаваемые на электродвигатель системы агитации пульпы и электронагревательный элемент термостата напряжения, через заданные интервалы времени. Данные сохраняются в файле в формате, удобном для последующего импортирования их в программу Microsoft Office Excel для анализа и построения графиков. В случае непреднамеренного отклонения любого из параметров от нормы сработает оповещение оператора посредством отправки сообщения на один или несколько заранее запрограммированных номеров телефона с указанием даты, времени и значения соответствующего параметра. Кроме того, будет сделана такая же внеочередная запись в файл журнала на карте памяти.

Применение микроконтроллерного управления особенно удобно, поскольку позволяет в будущем совершенствовать управляющую программу, придавая тем самым реактору новые возможности и функции. Например, при необходимости в процессе эксперимента циклично плавно или скачкообразно изменяя тот или иной параметр в течение определенного интервала времени, можно заранее составить необходимую программу и занести ее в память микроконтроллера, а затем удаленно в произвольный момент времени контролировать ситуацию посредством GSM-связи и в любое удобное время считывать информацию из журнала на карте памяти.

Заключение. Таким образом, разработанный нами реактор для бактериально-химического выщелачивания сульфидных медно-никелевых руд и концентратов может использоваться также в исследованиях других бактериально-химических процессов. 


\section{ЛИТЕРАТУРА}

1. Балыков А.А. Исследования бактериально-химического выщелачивания сульфидной медно-никелевой руды в проточном режиме / А.А.Балыков, Ю.П.Трухин // Горный информационно-аналитический бюллетен). 2014. Отдельный выпуск 2 «Камчатка». С. 290-299.

2. Теляков Н.М. Перспективы применения биотехнологий в металлургии и обогащении / Н.М.Теляков, А.А.Дарьин, В.А.Луганов // Записки Горного институга. 2016. Т. 217. С. 113-124.

3. Хайнасова Т.С. Бактериально-химическое выщелачивание как экологически безопасный способ переработки сульфидной кобальт-медно-никелевой руды / Т.С.Хайнасова, О.О.Левенец // Разведка и охрана недр. 2015. № 1. С. $49-54$.

4. A review of sulfide minerals microbially assisted leaching in stirred tank reactors / A.Mahmoud, P.Cezac, A.F.A.Hoadley, F.Contamine, P.d'Hugues // International Biodeterioration \& Biodegradation. 2017. Vol.119. P.118-146. DOI: 10.1016/j.ibiod.2016.09.015

5. Brierley J.A. Present and future commercial applications of biohydrometallurgy / J.A.Brierley, C.L.Brierley // Hydrometallurgy. 2001. Vol. 59. P. 233-239. DOI: 10.1016/S0304-386X(00)00162-6

6. Bioleaching of a chalcopyrite concentrate with moderate thermophilic microorganisms in a continuous reactor system / L.Cancho, M.L.Blazquez, A.Ballester, F.Gonzalez, J.A.Munoz // Hydrometallurgy. 2007. Vol. 87. P. 100-111. DOI: 10.1016/j.hydromet.2007.02.007

7. Bioleaching of a low grade nickel-copper-cobalt sulfide ore / C.Yang, W.Qin, S.Lai, J.Wang, Y.Zhang, F.Jiao, L.Ren, T.Zhuang, Z.Chang // Hydrometallurgy. 2011. Vol. 106. P. 32-37. DOI: 10.1016/j.hydromet.2010.11.013

8. Continuous bioleaching of a pyrite concentrate in stirred reactors: Population dynamics and exopolysaccharide production vs. bioleaching performance / P.d'Hugues, C.Joulian, P.Spolaore, C.Michel, F.Garrido, D.Morin // Hydrometallurgy. 2008. Vol. 94. P. 34-41. DOI: 10.1016/j.hydromet.2008.05.045

9. Gericke M. Bioleaching strategies for the treatment of nickel-copper sulphide concentrates / M.Gericke, Y.Govender // Minerals Engineering. 2011. Vol. 24. P. 1106-1112. DOI: 10.1016/j.mineng.2011.02.006

10. Pogaku R. Optimization of bacterial oxidation process parameters for selective leaching of nickel by Thiobacillus ferrooxidans / R.Pogaku, B.Kodali // International Journal of Chemical Reactor Engineering. 2006. Vol. 4. N 1. P. 1307-1314.

11. Rawlings D.E. Industrial practice and the biology of leaching of metals from ores // Journal of Industrial Microbiology and Biotechnology. 1998. Vol. 20. P. 268-274.

12. Tank bioleaching of copper from combined flotation concentrate and smelter dust / A.B.Vakylabad, M.Ranjbar, Z.Manafi, F.Bakhtiari // International Biodeterioration \& Biodegradation. 2011. Vol. 65. P. 1208-1214. DOI: 10.1016/j.ibiod.2011.09.006

13. Watling H.R. The bioleaching of sulphide minerals with emphasis on copper sulphides - A review // Hydrometallurgy. 2006. Vol. 84. P. 81-108. DOI: 10.1016/j.hydromet.2006.05.001

14. Watling H.R. The bioleaching of nickel-copper sulfides // Hydrometallurgy. 2008. Vol.91. P.70-88. DOI: 10.1016/j.hydromet.2007.11.012

15. Watling H.R. Review of biohydrometallurgical metals extraction from polymetallic mineral resources // Minerals. 2015. Vol. 5. P. 1-60. DOI: $10.3390 / \min 5010001$

Aвторы: А.А.Балыков, научный сотрудник, апа-bio-z@yandex.rи (Научно-исследовательский геотехнологический иентр Дальневосточного отделения Российской академии наук, Петропавловск-Камчатский, Россия), О.О.Левенец, канд. техн. наук, старший научный сотрудник, leveolga@yandex.rи (Научно-исследовательский геотехнологический центр Дальневосточного отделения Российской академии наук, Петропавловск-Камчатский, Россия), Т.С.Хайнасова, канд. биол. наук, стариий научный сотрудник, khainasova@yandex.rи (Научно-исследовательский геотехнологический иентр Дальневосточного отделения Российской академии наук, Петропавловск-Камчатский, Россия).

Статья поступила в редакиию 02.03.2018.

Статья принята к публикачии 11.05.2018. 